\title{
Ocular trauma by kinetic impact projectiles during civil unrest in Chile
}

\author{
Álvaro Rodríguez $\mathbb{1 D}^{1} \cdot$ Sebastián Peña ${ }^{2,3} \cdot$ Isabel Cavieres ${ }^{1} \cdot$ María José Vergara $^{1} \cdot$ Marcela Pérez $^{1} \cdot$ Miguel Campos $^{1}$. \\ Daniel Peredo ${ }^{1} \cdot$ Patricio Jorquera ${ }^{4} \cdot$ Rodrigo Palma $^{4} \cdot$ Dennis Cortés $^{5} \cdot$ Mauricio López $^{1} \cdot$ Sergio Morales $^{1}$
}

Received: 13 May 2020 / Revised: 17 July 2020 / Accepted: 12 August 2020 / Published online: 24 August 2020

(c) The Author(s), under exclusive licence to The Royal College of Ophthalmologists 2020

\begin{abstract}
Background The use of kinetic impact projectiles (KIPs) for crowd-control has increased worldwide. Despite having been created as non-lethal weapons, significant damage to several organs, including the eye, has been reported. In this study, we investigated cases of ocular trauma from KIPs during the civil unrest in Chile. To our knowledge, this is the largest case series recorded in international literature.

Methods We included all patients who sought care or were referred to the Eye Trauma Unit, a national referral centre in Santiago, Chile, during the civil unrest from October 18 to November 30, 2019. We reviewed paper medical records and extracted data on suspected cause of trauma, type of trauma, visual acuity and sociodemographic data.

Results We included 259 patients, out of which in 182 cases (70.5\%) KIPs were the suspected cause. Cases by KIPs were predominantly male (86.6\%), young (median age 26.3, interquartile range 22.0-31.4) and living in the Metropolitan Region. Eighty-nine patients (48.9\%) had severe visual impairment or were blind at the first examination. The trauma was an openglobe injury in $20.3 \%$ of cases and 13 cases required evisceration of the ocular content. Compared to other causes of ocular trauma, KIPs were related to a more severe loss of visual acuity and a higher frequency of open-globe injuries.

Conclusions The use of KIPs during a period of civil unrest in Chile resulted in severe ocular trauma, visual impairment and permanent disability. KIPs should be avoided as a method of crowd-control.
\end{abstract}

Supplementary information The online version of this article (https:// doi.org/10.1038/s41433-020-01146-w) contains supplementary material, which is available to authorized users.

Álvaro Rodríguez

alvaro.rovega@ug.uchile.cl

1 Eye Trauma Unit, Hospital del Salvador, University of Chile, Avenida Salvador 364, Santiago, Chile

2 Department of Public Health Solutions, Finnish Institute for Health and Welfare, Mannerheimintie 166, Helsinki, Finland

3 Facultad de Medicina, University Diego Portales, Ejército 233, Santiago, Chile

4 Department of Mechanical Engineering, Faculty of Engineering, University of Chile, Blanco Encalada 2002, Santiago, Chile

5 Department of Ophthalmology, Pontificia Universidad Católica de Chile, Avenida Vicuña Mackenna 4686, Santiago, Chile

\section{Introduction}

Crowd-control weapons (CCWs) are less-lethal weapons used by law enforcement agencies as a method of limiting the escalation of a conflict to minimize the number of casualties. Since its introduction in 1970 [1], the use of kinetic impact projectiles (KIPs), a type of CCW designed to incapacitate individuals by inflicting pain or sublethal injury [2], has been reported in a growing number of countries where social protests have arisen, including France, Spain, Hong Kong, Lebanon and Argentina [3-7]. Even though the COVID-19 pandemic has reduced mobility in general, the killing of George Floyd in the United States has resulted in massive protests and at least 20 reported cases of ocular trauma [8].

Chile, one of the most developed countries in Latin America, recently experienced an outburst of civil unrest not seen since the return of democracy in 1990. On October 6, 2019, the Chilean government announced a raise in the transport fare in the Metropolitan Region. The announcement ignited massive evasion of the subway fare in 
Santiago, which started on October 11 and grew slowly over the subsequent days. On October 18, these mass evasions escalated into a nationwide movement against abuse, social injustice and inequality, resulting in large demonstrations and violence in Chile's major cities. On October 19 , after a night of social riots, arson of subway stations and vandalization of public spaces, President Sebastián Piñera declared a State of Emergency, granting the Military control of public safety.

To control the civil unrest, the Chilean police force used water cannon trucks, tear gas and pepper spray, batons and KIPs, i.e., "rubber bullets" (baton rounds) and bean bag rounds. The Chilean police force controlled the demonstrations violently, resulting in 11,180 people injured and 1974 with gunshot wounds [9]. Ophthalmologists in trauma units noticed a rise in ocular trauma already on October 19; from October 22, the Eye Trauma Unit at the Hospital del Salvador, in association with the Chilean Medical Association and the Chilean Society of Ophthalmology, producing a daily report warning about the drastic increase of cases of ocular trauma. On November 10, the National Police Director issued an order limiting the use of KIPs. On November 15, a study was released of a chemical analysis of the bullets, showing a different composition than the one declared by the National Police Force, resulting in their partial ban on November 19 [10]. A detailed account of the timeline of events can be found in Table S1.

Despite its intention to inflict only superficial painful injuries, KIPs can cause significant morbidity and mortality, much of it from penetrative injuries and head, neck and torso trauma, including severe ocular trauma [2]. Previous studies have described injuries arising from long-term periods of civil unrest in Northern Ireland in 1970-1975 [1, 11] and Israel and the Palestinian Territories in 1987-1993 and 2000 [12-14]. More recently, trauma from less-lethal weapons have been described in short-term civil demonstrations in France [15], India [16], Turkey [17] and Nepal [18]. Few of these reports have provided an in-depth description of ocular trauma, even though severe ocular trauma represents a significant global health problem, being, in some series, the main cause of monocular blindness [12].

In this study, we investigated cases of ocular trauma from KIPs during the civil unrest in Chile between October 18 and November 30, 2019. We used data from the national reference centre in ocular trauma (Eye Trauma Unit) at the Hospital del Salvador in Santiago, Chile. We described the suspected cause and visual impairment, as well as the socio-demographic and ophthalmologic characteristics of the patients. This is the largest case series of ocular injuries due to KIPs in the international literature to date in a very short period.

\section{Methods}

\section{Study design}

We carried out a cross-sectional study of all patients who sought care or were referred to the Eye Trauma Unit at the Hospital del Salvador in Santiago, Chile. The Eye Trauma Unit is the national reference centre for ocular trauma and the only ocular trauma centre in the Metropolitan Region, covering a total of 13.4 million beneficiaries of public health insurance (FONASA).

\section{Participants}

We analysed paper medical records of all patients with ocular trauma occurred between October 18 and November 30, 2019.

\section{Variables}

We recorded the suspected cause of trauma based on clinical history, physical examination, complementary examinations and surgical findings, which had to be concordant. We classified the trauma mechanism into open and closed globe trauma, following the standardized classification of ocular trauma [19].

We obtained additional information on visual acuity (VA), type of trauma, primary and secondary diagnosis and type of surgery when applicable. Ophthalmic technologists (OT) measured the VA using the Electronic Early Treatment for Diabetic Retinopathy Study visual acuity test with a NIDEK SC-2000 system chart, calibrated at $5 \mathrm{~m}$ of distance [20]. The procedure included testing each eye separately while wearing any current distance spectacles. If the patient failed to see the largest optotype, the OT continued testing for VA of counting fingers, hand movement or light perception. The pinhole occluder was used in all cases when VA was between 20/25 and counting fingers. We classified VA data in seven categories using the International Classification of Diseases version 11: category 0 (no visual impairment, VA $20 / 20$ to 20/40), category 1 (mild visual impairment, defined as VA of 20/40 to 20/70), category 2 (moderate visual impairment, defined as VA of 20/70 to 20/ 200), category 3 (severe visual impairment, defined as VA of 20/200 to 20/400), category 4 (blindness, defined as VA of 20/400 to 20/1200 or count fingers at $1 \mathrm{~m}$ ) and category 5 (blindness, defined as VA of 20/1200 to light perception) and category 6 (blindness, defined as no light perception). Categories 4-6 are considered blindness [21].

Patients were diagnosed and treated by a staff ophthalmologist alone or with the assistance of an ophthalmology resident following the national protocol on severe ocular trauma [22]. We registered whether there was a computed 
tomography (CT), B-scan ultrasonography or both. These exams were used to identify the presence of intraocular damage in cases in which eye fundus assessment was not possible.

We extracted information on sociodemographic variables from the medical records, including age, gender and area of residence (Metropolitan Region and others). We used social insurance as a proxy for socioeconomic status. We classified social insurance into private (ISAPRE) or public (FONASA); the public insurance was further classified into four categories defined by the National Health Fund: no income (category A); monthly income lower than US $\$ 331.4$ (category B); monthly income higher than USD\$331.4 but lower than USD\$ 454.6 (category C) and monthly income higher than USD $\$ 454.6$ (category D).

\section{Statistical methods}

We used descriptive statistics to characterize the type of ocular trauma, severity and sociodemographic characteristics of patients. We used independent samples $t$-test to compare continuous variables and Pearson's chi-square test to compare categorical variables. For time trends, we used the date of occurrence of the trauma. We used $R$ version 3.6.2 for all analysis. The $\mathrm{R}$ markdown file can be found in the Supplementary Appendix.

\section{Results}

Between October 18 and November 30, a total of 259 patients sought care due to ocular trauma at the Eye Trauma Unit. KIPs were the suspected cause in 182 cases $(70 \cdot 5 \%)$. Other suspected causes were tear or pepper gas (36 cases); blunt trauma with baton, fists or other tools (18 cases); water tanks (10 cases); firearms ( 4 cases); and falls ( 1 case). We could not establish the suspected cause in 8 cases. All cases of ocular trauma by KIPs were secondary to the impact of baton rounds of $8 \mathrm{~mm}$ diameters with a cartridge of 12 bullets each (Fig. 1).

Table 1 shows the characteristics of patients by suspected cause of trauma. Patients with ocular trauma caused by KIPs were young (median age 26.3, interquartile range 22.0-31.4), more often male and from the Metropolitan Region. Cases were almost equally distributed among different categories of the public health insurance and also $11.5 \%$ had private health insurance. Thirty-three cases had total blindness and 90 cases $(49.5 \%)$ had severe visual impairment or were blind at first examination (WHO categories 3 to 6). Around 20\% of the cases caused by KIPs had open-globe trauma. Compared to other suspected causes of trauma, patients with trauma caused by KIPs were younger, more often

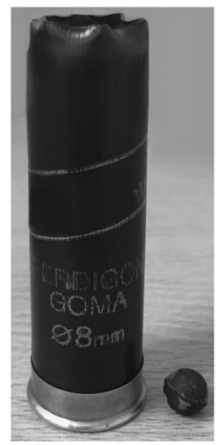

Fig. 1 KIPs with its cartridge.Each cartridge contains twelve $8 \mathrm{~mm}$ baton rounds. The logo was removed using a photo editing software.

lived in other regions, had a lower VA and had more often open-globe injuries.

Table 2 shows the ophthalmologic characteristics of the patients. All cases were unilateral except by one case, an 18year-old man with an open globe injury in one eye and an intraorbital foreign body in the contralateral eye. Closedglobe injury was the most common primary diagnosis. Traumatic uveitis, hyphema, vitreous haemorrhage and eyelid laceration was the most common secondary diagnosis in closed-globe trauma. There were 105 surgical procedures performed in 91 patients. The most common surgical procedures was the removal of the intraorbital foreign body $(48.6 \%)$, followed by the repair of open globe injury. Thirteen patients required evisceration of the ocular content, and, therefore, experienced permanent monocular blindness.

The time trends show the incidence of new cases of ocular trauma during the study period (Fig. 2). Around half of the cases $(48.4 \%)$ due to KIPs occurred during the beginning of the civil unrest and the State of Emergency, with peaks on October 21, 24 and 28 and November 8, 12 and 15. Cases of ocular trauma continued despite warnings by civil society and medical authorities (since October 22) and the limitation in the use of KIPs issued by the police force (on November 10). There were nine cases recorded after the total ban on November 19 .

\section{Discussion}

We investigated cases of ocular trauma from KIPs during the civil unrest in Chile between October 18 and November 30, 2019. We obtained data from medical records from the national reference centre and only Eye Trauma Unit in the Metropolitan Region. KIPs were the largest suspected cause of ocular trauma, affecting primarily young males and causing both open and closedglobe trauma. Visual acuity at the first examination was very poor in a large proportion of cases. 
Table 1 Characteristics of 251 patients with ocular trauma at the Eye Trauma Unit in Hospital del Salvador, Santiago, Chile, between October 18 and November 30, 2019.

\begin{tabular}{|c|c|c|c|}
\hline & $\begin{array}{l}\text { Kinetic impact } \\
\text { projectile }\end{array}$ & $\begin{array}{l}\text { Other } \\
\text { mechanism }\end{array}$ & $P$ value \\
\hline$n^{\mathrm{a}}$ & 182 & 69 & \\
\hline Age (median (IQR)) & $26.3(22.0-31.4)$ & $31.8(25.3-43.0)$ & \\
\hline Age categories & & & 0.004 \\
\hline Less than 18 years & $15(8.3)$ & $5(7.2)$ & \\
\hline $18-35$ years & $137(75.7)$ & $39(56.5)$ & \\
\hline $35-50$ years & $23(12.7)$ & $17(24.6)$ & \\
\hline Over 50 years & $6(3.3)$ & $8(11.6)$ & \\
\hline Female, \% & $19(10.4)$ & $11(15.9)$ & 0.23 \\
\hline $\begin{array}{l}\text { Residence in Metropolitan } \\
\text { Region, \% }\end{array}$ & $153(84.1)$ & $65(94.2)$ & 0.034 \\
\hline Type of health insurance & & & 0.66 \\
\hline FONASA A & 34 (18.7) & $13(18.8)$ & \\
\hline FONASA B & 39 (21.4) & 17 (24.6) & \\
\hline FONASA C & $41(22.5)$ & $10(14.5)$ & \\
\hline FONASA D & $40(22.0)$ & $20(29.0)$ & \\
\hline ISAPRE & $21(11.5)$ & $6(8.7)$ & \\
\hline No insurance or PRAIS & $7(3.8)$ & $3(4.3)$ & \\
\hline Visual acuity & & & 0.01 \\
\hline 0 (no impairment) & $69(37.9)$ & $31(46.3)$ & \\
\hline 1 (mild impairment) & $11(6.0)$ & $9(13.4)$ & \\
\hline 2 (moderate impairment) & $12(6.6)$ & $7(10.4)$ & \\
\hline 3 (severe impairment) & $5(2.7)$ & $5(7.5)$ & \\
\hline 4 (blindness) & $13(7.1)$ & $2(3.0)$ & \\
\hline 5 (blindness) & $39(21.4)$ & $10(14.9)$ & \\
\hline 6 (blindness) & $33(18.1)$ & $3(4.5)$ & \\
\hline Diagnosis & & & 0.002 \\
\hline Open-globe & $37(20.3)$ & $11(15.9)$ & \\
\hline Closed trauma & $141(77.5)$ & $49(71.0)$ & \\
\hline Unknown & $4(2.2)$ & $9(13.0)$ & \\
\hline
\end{tabular}

Data are median (interquartile range (IQR)) or count (\%). FONASA A, $\mathrm{B}, \mathrm{C}$ and $\mathrm{D}$ are the public health insurance categories. ISAPRE is the private health insurance. PRAIS is a program for victims of torture during the Military Dictatorship (1973-1989).

${ }^{\mathrm{a}}$ The suspected cause was unknown in eight cases.

We observed a large number of ocular trauma cases caused by the impact by KIPs in a very short period of time (42 days), a phenomenon not observed previously in Chile or the international literature. The number of cases reported here is the largest described to date, more than those reported in Israel during the first Intifada between 1987 and 1993 (157 cases) [12] or during the Yellow Vest demonstrations in France between 2016 and 2019 (43 cases) [23].

Our study shows that most patients were young men. This is in line with findings in other settings and likely reflects the age distribution of the demonstrators. We found a high rate of patients who were less than 18 years old $(8.1 \%)$, which has also been reported in Israel and the Palestinian Territories and France [12, 23].

Visual acuity is the most important prognostic factor in ocular trauma $[24,25]$. The proportion of patients without
Table 2 Ophthalmologic characteristics of 182 patients with ocular trauma by KIPs at the Eye Trauma Unit in Hospital del Salvador, Santiago, Chile, between October 18 and November 30, 2019.

\begin{tabular}{|c|c|}
\hline & Ocular trauma characteristics \\
\hline Compromised eye & $\begin{array}{l}\text { Right eye: } 91(50 \%) \\
\text { Left eye: } 90(49.5 \%) \\
\text { Both eyes: } 1(0.5 \%)\end{array}$ \\
\hline Primary trauma diagnosis & $\begin{array}{l}\text { Closed-globe injury: } 89(48.9 \%) \\
\text { Intraorbital foreign body injury: } 52 \\
(28.6 \%) \\
\text { Open-globe injury only: } 20(11 \%) \\
\text { Open-globe injury and intraorbital } \\
\text { foreign body: } 17(9.3 \%) \\
\text { Others: } 4(2.2 \%)\end{array}$ \\
\hline $\begin{array}{l}\text { Secondary diagnostic of closed- } \\
\text { globe trauma }\end{array}$ & $\begin{array}{l}\text { Traumatic uveitis: } 45(31.9 \%) \\
\text { Hyphema: } 42 \text { (29.8\%) } \\
\text { Vitreous haemorrhage: } 35(24.8 \%) \\
\text { Eyelid laceration: } 32(22.7 \%) \\
\text { Orbital fracture: } 7(5 \%) \\
\text { Macular hole: } 5 \text { (3.5\%) } \\
\text { Retinal haemorrhage: } 12(8.5 \%) \\
\text { Corneal oedema: } 7 \text { (5\%) } \\
\text { Berlin's oedema: } 18 \text { (12.8\%) } \\
\text { Commotio retinae: } 34 \text { (24.1\%) } \\
\text { Chorioretinitis sclopetaria: } 11(7.8 \%) \\
\text { Ocular hypertension: } 7(5 \%) \\
\text { Retinal detachment: } 5(3.5 \%) \\
\text { Traumatic cataract: } 6(4.3 \%) \\
\text { Conjunctival laceration: } 9(6.4 \%) \\
\text { Scleral partial laceration: } 2(1.4 \%) \\
\text { Crystalline lens dislocation: } 2(1.4 \%) \\
\text { Iridodialysis: } 4 \text { (2.8\%) } \\
\text { Corneal partial laceration: } 1(0.7 \%)\end{array}$ \\
\hline Surgery & $\begin{array}{l}\text { Removal of intraorbital foreign body: } 51 \\
(48.6 \%) \\
\text { Repair of open-globe injury: } 18 \text { (17.1\%) } \\
\text { Evisceration: } 13(12.4 \%) \\
\text { Pars plana vitrectomy: } 6(5.7 \%) \\
\text { Eyelid laceration: } 5(4.7 \%) \\
\text { Lateral canthotomy and cantholysis: } \\
2(1.9 \%) \\
\text { Conjunctival laceration: } 4(3.8 \%) \\
\text { Others: } 6(5.7 \%)\end{array}$ \\
\hline
\end{tabular}

light perception (i.e., the lower level of VA) was lower than those reported in Northern Ireland [1], Israel [14] or France [23]. However, the proportion of cases of ocular trauma by KIPs with VA equal or lower than 20/100 was higher than those reported in Israel [12, 14], but lower than those reported in France [23].

We found that around 20\% of cases had open-globe trauma. This is similar to reports in Nepal [18] and lower than previous studies in Northern Ireland, India, France and Israel $[1,14,16,23]$. The damage from KIPs depends on the composition, size, weight and shooting distance. The KIPs used by the Chilean police force were initially said to be rubber bullets; however, ophthalmologists at 


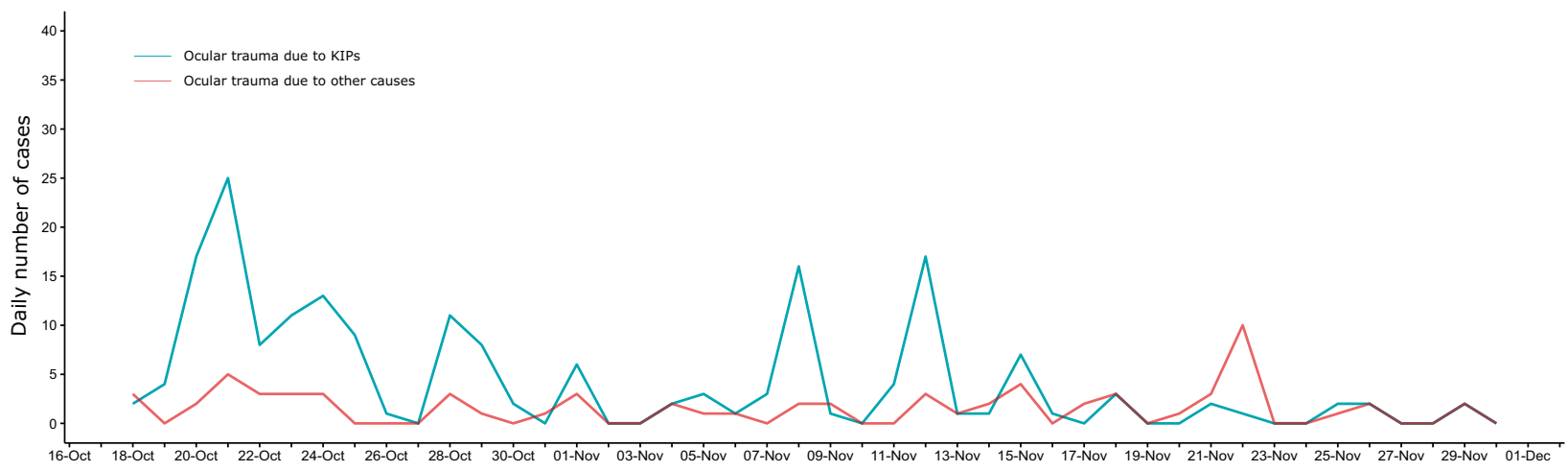

Fig. 2 Daily number of ocular trauma cases, by suspected cause, during a period of civil unrest in Chile (October 18 - November 30, 2019). The blue line represents cases of ocular trauma caused by KIPs, while the red line represents all other cases.

the Eye Trauma Unit noticed that the projectiles showed a metallic density and produced a hardening and scatter beam artefact in the CT of the orbit. A chemical study of KIPs showed that the KIPs in Chile consisted of $20 \%$ rubber and $80 \%$ other compounds, including silica, barium sulphate and lead. A physical analysis confirmed a higher hardness than rubber [10]. The police protocol instructs KIPs to be used $30 \mathrm{~m}$ away from the objective, yet these results indicate that, given the hardness of the KIPs used in Chile, these are more likely to produce open-globe injury even if shot according to police protocol [26, 27].

We found that about half of the cases occurred during the State of Emergency and curfew between October 19 and October 26. Cases of ocular trauma due to KIPs continued to occur despite the warnings from the Eye Trauma Unit, Chilean Medical Association and the Chilean Society of Ophthalmology, the limitation in their use issued by the National Police Director and even after their total ban.

Our study has several strengths. First, we examined cases from the largest national referral centre and the only eye trauma unit in the Metropolitan Region. Second, we used a standardised classification of ocular trauma, objective scales to assess VA and all patients were evaluated by a staff ophthalmologist alone or with the assistance of an ophthalmology resident, reducing the risk of measurement error. Third, as the events occurred in a brief period of time, we are able to establish with reasonable precision the time of ocular trauma.

However, there are limitations to this study. The Eye Trauma Unit is a public institution and most of the patients have public health insurance. Our data cover $74.4 \%$ of all cases in the country during the study period [9] and, therefore, our estimates might not represent cases in other regions or with private health insurance. Second, more severe cases are more likely to seek health care. Our cases are probably an underestimation of the total number of cases and of higher severity. However, as severe ocular trauma is covered by the Regime of Explicit Guarantees, which guarantees treatment access and financial protection, we considered unlikely that patients with severe ocular injuries have not sought health care. Third, given we measured VA at the first examination, we cannot ascertain that all the cases of blindness are permanent, except for those that required evisceration.

\section{Public health implications}

Our study shows that KIPs for crowd-control are not fulfilling their purpose to avoid severe and fatal injuries, leading to visual impairment and eventually blindness in a large number of cases. KIPs appear not to be safe even if shot following the established protocol (at more than $30 \mathrm{~m}$ of distance and without aiming at the head), given their unpredictable trajectory and hardness. Ocular trauma from KIPs continued even after the warnings from civil society and national and international media and even after a partial and total ban of their use, indicating a breach in the protocol by the police force and the failure of the Chilean government to react to the violation of the protester's human rights. The experience of Chile provides a cautionary tale about the use of KIPs during social protests.

\section{Conclusions}

The use of KIPs resulted in severe ocular trauma, visual impairment and permanent disability. KIPs should be avoided as a method of crowd-control. Future research should explore the long-term prognosis of ocular trauma caused by KIPs. 


\section{Summary}

\section{What was known before}

- The use of kinetic impact projectiles (KIPs) for crowdcontrol has increased worldwide. The KIPs can produce damage to several organs, including the eye.

\section{What this study adds}

- This is the largest case series of ocular trauma recorded in the international literature.

- The use of KIPS during a period of civil unrest in Chile resulted in severe ocular trauma, visual impairment and permanent disability.

- KIPs should be avoided as a method of crowd-control.

Acknowledgements We are grateful to Mika Siuko and Paula Sierralta for their thoughtful comments on an earlier draft of the manuscript.

\section{Compliance with ethical standards}

Conflict of interest The authors declare that they have no conflict of interest.

Ethics We obtained the approval from the Scientific Ethics Committee from the East Metropolitan Health Service in accordance with Law 20120 (2006).

Publisher's note Springer Nature remains neutral with regard to jurisdictional claims in published maps and institutional affiliations.

\section{References}

1. Millar R, Rutherford WH, Johnson S, Malhotra VJ. Injuries caused by rubber bullets: a report on 90 patients. Br J Surg. 1975;62:480-6. https://doi.org/10.1002/bjs.1800620613.

2. Haar RJ, Iacopino V, Ranadive N, Dandu M, Weiser SD. Death, injury and disability from kinetic impact projectiles in crowdcontrol settings: a systematic review. BMJ Open. 2017;7:e18154. https://doi.org/10.1136/bmjopen-2017-018154.

3. Amnesty International. France: calls for suspending the use of rubber bullets fired with the LBD40 and for banning grenades GLI-F4 in the context of policing protests. (2019). https://www. amnesty.org/en/documents/eur21/0304/2019/en/. Accessed 16 Dec 2019.

4. Jones S, Burgen S. Catalan referendu: "Police threw us aside... and more vanloads arrived", The Guardian. Available at https://www. theguardian.com/world/2017/oct/01/police-started-throwing-us-a side-more-and-more-vanloads-arrived. Accessed 16 Dec 2019.

5. Reuters Investigates. Weapons of mass control, tactics of mass resistance, Reuters, October 31, 2019. Available at https://www. reuters.com/investigates/special-report/hong-kong-protestsviolence/. Accessed 16 Dec 2019.

6. Associated Press. Lebanon protests roll into second day amid police crackdown, The Guardian, Dec, 2019. Available at https://www.theguardian.com/world/2019/dec/15/offices-of-two- major-parties-set-on-fire-lebanons-state-run-agency-reports. Accessed 16 Dec 2019.

7. Burin G, Health M. Argentine police fire rubber bullets at antiausterity protesters, Reuters. Available at https://www.reuters. com/article/us-argentina-budget/argentine-police-fire-rubberbullets-at-anti-austerity-protesters-idUSKCN1MY2KA. Accessed 16 Dec 2019.

8. Bauerlein, V, Calvert, S. Serious Eye Injuries at Protests Spur Calls to Ban Rubber Bullets, Wall Street Journal, June, 2020. Available at https://www.wsj.com/articles/serious-eye-injuries-spur-calls-to-banrubber-bullets-11592070374. Accessed 8 Jul 2020.

9. Instituto Nacional de Derechos Humanos. Informe Anual sobre la situación de los Derechos Humanos en Chile en el contexto de la crisis social Instituto Nacional de Derechos Humanos, 2019.

10. Jorquera, P, Palma, R. Estudio de perdigón. Informe final (UTO) 15/11/2019. Departamento de Ingeniería Mecánica, Facultad de Ciencias Físicas y Matemáticas, Universidad de Chile (2019). http://ingenieria.uchile.cl/noticias/159269/ perdigones-usados-por-carabineros-contienen-80-de-metales. Accessed 21 Jan 2020.

11. Rocke L. Injuries caused by plastic bullets compared with those caused by rubber bullets. Lancet. 1983;1:919-20. https://doi.org/ 10.1016/s0140-6736(83)91340-5.

12. Jaouni ZM, O'Shea JG. Surgical management of ophthalmic trauma due to the Palestinian Intifada. Eye (Lond). 1997;11(Pt 3):392-7. https://doi.org/10.1038/eye.1997.83.

13. Hiss J, Hellman FN, Kahana T. Rubber and plastic ammunition lethal injuries: the Israeli experience. Med Sci Law. 1997;37:139-44. https://doi.org/10.1177/002580249703700209.

14. Lavy T, Asleh SA. Ocular rubber bullet injuries. Eye (Lond). 2003;17:821-4. https://doi.org/10.1038/sj.eye.6700447.

15. Lartizien R, Schouman T, Raux M, Debelmas A, LanciauxLemoine S, Chauvin A, et al. Yellow vests protests: facial injuries from rubber bullets. Lancet. 2019;394:469-70. https://doi.org/10. 1016/S0140-6736(19)31764-7.

16. Khan S, Maqbool A, Abdullah N, Keng MQ. Pattern of ocular injuries in stone pelters in Kashmir valley. Saudi J Ophthalmol. 2012;26:327-30. https://doi.org/10.1016/j.sjopt.2012.04.004.

17. Unuvar U, Yilmaz D, Ozyildirim I, Dokudan EY, Korkmaz C, Doganoglu S, et al. Usage of Riot Control Agents and other methods resulting in physical and psychological injuries sustained during civil unrest in Turkey in 2013. J Forensic Leg Med. 2017;45:47-52. https://doi.org/10.1016/j.jflm.2016.11.007.

18. Sharma AK, Shah DN, Shrestha JK, Thapa M, Shrestha GS. Ocular injuries in the people's uprising of April 2006 in Kathmandu, Nepal. Nepal J Ophthalmol. 2014;6:71-9. https://doi.org/ 10.3126/nepjoph.v6i1.10775.

19. Kuhn F, Morris R, Witherspoon CD, Heimann K, Jeffers JB, Treister G. A standardized classification of ocular trauma. Ophthalmology. 1996;103:240-3. https://doi.org/10.1016/s0161-6420(96)30710-0.

20. Beck RW, Moke PS, Turpin AH, Ferris FL, SanGiovanni JP, Johnson CA, et al. A computerized method of visual acuity testing: adaptation of the early treatment of diabetic retinopathy study testing protocol. Am J Ophthalmol. 2003;135:194-205. https:// doi.org/10.1016/S0002-9394(02)01825-1.

21. World Health Organization. International Classification of Diseases for Mortality and Morbidity Statistics (11th Revision, version: 04/2019). (2019). https://icd.who.int/browse11/l-m/en. Accessed 4 Jan 2019.

22. Ministerio de Salud. Guia Clínica Trauma Ocular Grave. Subsecretaría de Salud Pública, Ministerio de Salud, 2009.

23. Chauvin A, Bourges JL, Korobelnik JF, Paques M, Lebranchu P, Villeroy $\mathrm{F}$, et al. Ocular injuries caused by less-lethal weapons in France. Lancet. 2019;394:1616-7. https://doi.org/10.1016/S01406736(19)31807-0. 
24. Man CYW, Steel D. Visual outcome after open globe injury: a comparison of two prognostic models - the ocular trauma score and the classification and regression tree. Eye. 2010;24:84-9. https://doi.org/10.1038/eye.2009.16.

25. Kuhn F, Maisiak R, Mann L, Mester V, Morris R, Witherspoon CD. The Ocular Trauma Score (OTS). Ophthalmol Clin. 2002;15:163-5. https://doi.org/10.1016/S0896-1549(02)00007-X.
26. Maiden N. Ballistics reviews: mechanisms of bullet wound trauma. Forensic Sci Med Pathol. 2009;5:204-9. https://doi.org/ 10.1007/s12024-009-9096-6.

27. Carabineros de Chile. Disparos con escopeta antidisturbios, con empleo de cartuchería con perdigón de goma y sus efectos en la superficie del cuerpo humano. Departamento de Criminalística, Carabineros de Chile, 2012. 